\title{
Sacrospinous Fixation in the Gynecology Department of Hôpital du Mali
}

\section{Traoré Alassane ${ }^{1 *}$, Sissoko Abdoulaye ${ }^{2}$, Coulibaly Mamadou Bakary ${ }^{1}$, Traoré Soumana Oumar ${ }^{3}$, Sima Mahamadou4, Bocoum Amadou5, Traoré Soumaila6, Touré Moustapha1, Tegueté Ibrahima ${ }^{5}$, Traoré Youssouf ${ }^{5}$}

\author{
${ }^{1}$ Obstetrics and Gynecology Department at Hôpital du Mali, Bamako, Mali \\ ${ }^{2}$ Obstetrics and Gynecology Department at the Teaching Hospital Mère-Enfant, Bamako, Luxembourg \\ ${ }^{3}$ Obstetrics and Gynecology Department at the Referral Health Center Commune V, Bamako, Mali \\ ${ }^{4}$ Obstetrics and Gynecology Department at the Teaching Hospital Point G, Bamako, Mali \\ ${ }^{5}$ Obstetrics and Gynecology Department at the Teaching Hospital Gabriel Touré, Bamako, Mali \\ ${ }^{6}$ Obstetrics and Gynecology Department at the Regional Hospital of Sikasso, Sikasso, Mali \\ Email: *alassane200@yahoo.fr
}

How to cite this paper: Alassane, T., Abdoulaye, S., Bakary, C.M., Oumar, T.S., Mahamadou, S., Amadou, B., Soumaila, T., Moustapha, T., Ibrahima, T. and Youssouf, T. (2021) Sacrospinous Fixation in the Gynecology Department of Hôpital du Mali. Open Journal of Obstetrics and Gynecology, 11, 20-26.

https://doi.org/10.4236/ojog.2021.111003

Received: October 17, 2020

Accepted: January 17, 2021

Published: January 20, 2021

Copyright $\odot 2021$ by author(s) and Scientific Research Publishing Inc. This work is licensed under the Creative Commons Attribution International License (CC BY 4.0).

http://creativecommons.org/licenses/by/4.0/

(c) (i) Open Access

\begin{abstract}
Sacrospinous fixation (SSF) or Richter's intervention (RI) aims to treat genital prolapse by securing the posterior vaginal wall to the small sacrospinous ligament. It is performed by low approach and includes a dissection of the pararectal space, visual exposure of the sacrospinous ligament and a needle with strait needle holder with nonabsorbable threads. It is often associated with a more complex corrective procedure, including cystocele cure, vaginal hysterectomy and posterior myorrhaphy. The objective of this study is to report the results of SSF in the gynecology department of Hôpital du Mali. A descriptive study was conducted from September 2014 to September 2015 concerning 37 patients operated on for uterine prolapse (UP). All patients with grade III UP were included in our study in whom a unilateral hysterectomy (UH) and sacrospinous fixation (SSF) were performed. All the patients were scheduled. Preoperatively they had benefited from an assessment and a pre-anesthetic consultation. Hospitalization of at least 24 hours prior to the operation was required. Postoperative follow-up was two years with a physical examination at 3 months, 9 months and 15 months, and phone calls between physical consultations. During the study period, we performed 37 RIs. The mean age of the patients was 48 years with extremes of 41 to 73 years. The large multiparity was found out in 35 cases (94.59\%), the pauciparous were two with 3 deliveries for each. Long labor of more than 18 hours was found out in 9 patients (24.32\%) and home delivery in 13 cases (35.13\%). The duration of the occurrence of prolapse was at least two years and 35 patients
\end{abstract}


were going through menopause. The type of anesthesia used for the surgery was spinal anesthesia for all patients. The average duration of the operation was 90 minutes. Complications occurred in three patients or $8.10 \%$ of cases, two cases of acute urine retention and one case of hematoma of the para-rectal space. The medium time of hospital stay was 5 days. The anatomical result was satisfactory in all patients. However, two patients presented with grade II rectocele one year after the operation. Sacrospinous fixation is a technique suitable for our patients who present with genital prolapse with extreme laxity of the suspension ligaments. Well done, it brings anatomical satisfaction and its complications are rare and slight.

\section{Keywords}

Sacrospinous Fixation, Genital Prolapse, Hôpital du Mali

\section{Introduction}

The surgical principle of fixing the vagina to a bone or ligament element to treat prolapse is an old one. It was described by Zweifel [1] then by Amreich who fixed the vagina to the great sacrosciatic ligament [2]. Richter modified the technique using the small sacrosciatic ligament [3]. Sacrospinous fixation (SSF) or Richter's intervention (RI) aims to treat genital prolapse by securing the posterior vaginal wall to the small sacrospinous ligament. It is performed by low approach and includes a dissection of the pararectal space, visual exposure of the sacrospinous ligament and a needle with strait needle holder with non-absorbable threads. It is often associated with a more complex corrective procedure, including cystocele cure, vaginal hysterectomy and posterior myorrhaphy. Despite the rarity of recurrences after RI, it is not routinely performed in the treatment of prolapse. From September 1990 to September 2002, J-P Estrade et al. [4] performed 92 RIs in France. In Mali, our research did not allow us to find out data on the practice of this intervention.

The objective of this paper is to report the results of sacrospinous fixation in the gynecology department of Hôpital du Mali.

\section{Material and Methods}

A descriptive study was conducted from September 2014 to September 2015 concerning 37 patients operated on for grade III uterine prolapse (UP).

The sampling was exhaustive and concerned all patients in whom sacrospinous fixation was performed. Any patients with grade III UP in whom a hysterectomy was performed were included. Any Patients in whom a simple prolapse treatment was performed without hysterectomy were excluded in our study.

Screening for cervical cancer by visual inspection after painting with acetic acid (IVA) and lugol (IVL) was performed in all patients.

The operation procedure was the same for all patients. After locoregional 
anesthesia (spinal anesthesia), we carried out the following steps:

$1^{\text {st }}$ step: A cystocele cure and a low level hysterectomy.

$2^{\text {nd }}$ step: Sacrospinous fixation: fixing the vaginal dome to the right sacrospinous ligament.

$3^{\text {rd }}$ step: A posterior colporrhaphy.

The parameters studied were age, parity, duration of prolapse, surgical complications, anatomical results and patient satisfaction.

The postoperative follow-up was two years with a physical examination at 3 months, 9 months and 15 months after the operation and phone calls between physical consultations.

\section{The Results}

During the study period, we performed 37 RIs. The average age of the patients was 48 years with extremes of 41 to 73 years. They were illiterate in 28 cases (75.67\%) of the primary level in 9 cases $(24.32 \%)$. The large multiparity was found out in 35 cases (94.59\%), the pauciparous were two with 3 deliveries for each. The parity was 6 . The notion of abnormal duration of labor was found out in 9 patients (24.32\%) and $13(35.13 \%)$ had performed at least one home birth. In the antecedents, forceps were applied in 4 patients (10.81\%), C-section 7 cases (18.91\%), macrosomia 11 cases (29.72\%) and fetal death in 13 cases (35.13\%). The duration of the occurrence of prolapse was at least two years and 30 patients were going through menopause. Screening for cervical cancer by visual acetic acid and lugol (VIA/IVL) methods was performed in all patients. Screening was negative in 35 cases (94.59\%). The biopsy was performed in both cases where the screening was positive. The histological result was one case of intraepithelial neoplasia (CIN2) and one case of planar condyloma.

On the operative level; the type of anesthesia used was spinal anesthesia and unilateral sacrospinous fixation on the woman's right side for all patients. The average duration of the operation was 90 minutes. No blood transfusion was performed. Postoperative complications had occurred in three patients, or $8.10 \%$ of cases, two cases of acute urine retention and one case of hematoma of the pararectal space. The mean time of hospital stay was 5 days. The anatomical result was satisfactory in all patients. However, two patients presented with grade II rectocele one year after the operation.

\section{Discussion}

Sacrospinous fixation has been widely described by different authors. The main idea is to attach the vaginal dome to a fixed element in order to prevent further prolapse. The Richter technique consists of attaching the vaginal dome to the uni or bilateral sacrospinous ligament. We performed 37 cases of unilateral sacrospinous fixation (USSF). Bilateral sacrospinous fixation (BSSF) has been performed in some series i.e. Pohl and Frattarelli studies [5]; David-Montefiore [6], but its real benefit has not been demonstrated. The unilateral Richter interven- 
tion (URI) versus BSSF certainly reduces morbidity and the duration of the intervention.

Population study: The characteristics of the patients are reported in Table 1 (age, pregnancy parity, surgical history, school background). The average parity of women was 6. That accounts for the genesis of genital prolapse, the main indication for Richter's intervention. Macrosomia, another important factor in the onset of prolapse, has been pointed out in the history of our patients. They are illiterate and have great difficulty in speaking about problems with the reproductive system. They keep the prolapse for a long time and only seek medical help when facing significant discomfort with an irreducible nature of the prolapse. The patients carried the prolapse for at least 2 years on average. The financial inaccessibility of health centers for adequate care partly explains this situation. The majority of our patients, 29 cases (78.37\%) resided outside Bamako, the city in which the care was effective. Our patients presented the four "Too many" at the origin of maternal death: the very high number of pregnancies (too many pregnancies), the early occurrence of pregnancies (too early), the very short interval between pregnancies (too close), and the occurrence of pregnancies at high ages (too late). The growing number of marriage in Malian society, particularly among young girls, can be the cause of teenage pregnancies.

In addition to poor monitoring of pregnancies, attempts and home deliveries, the delay in reaching health centers in an emergency are all factors that make pregnancy and childbirth in our context a real danger. The labor time could not be specified. The notion of abnormal labor time was found out in 9 patients (24.32\%). It is common to see parturients doing nearly 24 hours of labor or more. This situation contributes to increase the rates of maternal and fetal death. It also leads to consequences such as obstetric fistula and genital prolapse. Another aggravating factor is the high frequency of home births (Table 2).

The indications for RI: In our study all the patients $(n=37)$ were operated on for grade III UP. This is the major indication for SSF to prevent prolapse of the vaginal dome after hysterectomy. The indications for RI extended to:

Table 1 . The study population.

\begin{tabular}{ccc}
\hline & Means & Extremes \\
\hline Percentage & 48 years & $41-73$ \\
Patient ages & 06 & $03-11$ \\
Parity & 37 & 100 \\
Marital status & & \\
Level of study & 13 & 35.13 \\
History of home birth & 04 & 10.81 \\
Prior Forceps & 13 & 35.13 \\
History of stillbirths & 11 & 29.72 \\
History of macrosomia & &
\end{tabular}


Table 2. Intervention data.

\begin{tabular}{ccc}
\hline Number of intervention & 37 & 100 \\
Type: Left USSF & 37 & 100 \\
Mean time of intervention & 90 minutes & \\
Complications & 03 & 8.10 \\
- Acute urine retention & 02 & 5.40 \\
Pararectal space hematoma & 01 & 2.70 \\
Mean time of hospital stay & 5 days \\
\hline
\end{tabular}

Elytroceles: They constitute a good indication of SSF according to Ranney [7]. It is very often associated with a high rectocele.

Hysterocele: Severe hysterocele, witness to a complete insufficiency of the suspended ligaments, justifies intervention to support the pelvic wall.

Some authors have proposed RI as a preventive measure after vaginal hysterectomy when there are warning signs of prolapse, such as hyperlaxity of the cardinal and uterosacral ligaments [8] [9]. The benefit of such an intervention has not been established. This recommendation remains marginal and SSF is not systematic after vaginal hysterectomy. Vaginal dome prolapse after hysterectomy for benign uterine pathology has not been the subject of many published studies. The frequency of post-hysterectomy vaginal dome prolapse is estimated to be between $0.2 \%$ and $1 \%$ [1] [10]. J-P Estrade [11] in a series of 277 SSFs performed, vaginal dome prolapse was the indication in 92 cases, or $33.2 \%$.

The surgical intervention: All the patients underwent a total hysterectomy, USSF on the patient's right side. One single non-absorbable thread was used to fix the vagina to the sacrospinous ligament, and a posterior colporrhaphy. The feasibility of BSSF has been demonstrated in studies conducted by Polh and Frattarilli [5], and David Montefiore et al. [6], but its real benefit has not been demonstrated. A randomized study carried out in Blanc's department between 2003 and 2005 involved 72 patients (39 USSFs and 33 BSSFs) for whom the anatomical and functional evaluation was made one year after the operation. This study arrived at the conclusion that the anatomical and functional results observed between the two techniques are generally comparable. According to L. Cravello [12] for lack of sufficient data, it is difficult to recommend systematic BSSF in the current state of knowledge. The duration of the intervention in our study was 90 minutes. It concerns the entire intervention and not the only part of the SSF.

Complications: We did not distinguish between the complications of the various surgical procedures in general and those specifically pertaining to SSF. Three cases of complications were observed. These were two cases of acute urine retention, occurred suddenly on the $2^{\text {nd }}$ day of the operation after removal of the urinary catheter. Psychological management and the reset of the indwelling urinary catheter allowed total remission and a favorable outcome. We have kept the catheter for 3 days. And it was removed on the $4^{\text {th }}$ day. Patients were discharged 
on the $5^{\text {th }}$ day of the operation in good general condition. The other complication recorded was a hematoma of the pararectal space ( 1 case). This hematoma resolved spontaneously within 5 days and did not require further surgery. We did not record any bleeding complication that can increase morbidity and the duration of the operation. In SSF, the bleeding most often occurs by lesion of the pudendal nerve. The bleeding can be profuse and embarrassing. A tamponade with sterile compresses can usually stop it. When facing with significant and persistent bleeding, it is advisable to perform hemostasis and abandon the initial objective of performing SSF.

In the study by J.-P. Estrade [4] on the complications of SSF, on 277 patients who underwent SSF, the intraoperative complications were represented by one hemorrhagic accident and four rectal wounds. The main postoperative complications were perivaginal hematomas $(n=6)$ and pelvic abscesses $(n=2)$. The long-term symptomatology has consisted of perineal pain, sciatica, and dyspareunia.

In another study, results of SSF in the treatment of prolapse after J.-P. Estrade hysterectomy [11], the following complications were recorded: pararectal hematoma ( 1 case), acute retention of urine ( 3 cases), bladder wound ( 1 case), left ureteral complication (1 case).

Anatomical results: UP is a complex pathology that involves several elements. It is a benign condition that evolves over the long term. The results must also be judged over the long term. However, studies which assess the results after a follow-up of several years are rare [12].

Anatomical satisfaction in our study was $100 \%$ in the first year after surgery and $94.59 \%$ in the second year. Two patients presented with grade II cystocele. They did not feel any significant discomfort and did not want another operation. Our results are consistent with those of most authors. In 2005, L. Cravello pointed out in 92 patients, good anatomical results of $86.5 \%$ at four years [12]. The good results found in the literature are between $80 \%$ and $100 \%$, for a number of 30 to 123 patients and an average follow-up of one to ten years [13].

Patient satisfaction was $100 \%$. Even patients who had developed a cystocele one year after the procedure were satisfied. For patients who have had grade III UP for about two years, anatomical benefit is the main criterion for satisfaction. Patient satisfaction rates are very high in European series as well, although other considerations such as organ functionality, existence of pain are often assessed.

\section{Conclusion}

Sacrospinous fixation is adapted to the needs of our patients. It represents the gold standard in the surgical repair of grade III prolapse with hyperlaxity of the suspension ligaments.

\section{Conflicts of Interest}

The authors declare they have no conflict of interest. 


\section{References}

[1] Symmonds, R.E. and Pratt, J.H. (1960) Vaginal Prolapse Following Hysterectomy. American Journal of Obstetrics \& Gynecology, 79, 899-909. https://doi.org/10.1016/0002-9378(60)90684-0

[2] Amreich, I. (1951) Aetiologie und operation des scheidens-tumpfprolapses. Wien Klin Wochenschr, 63, 74-77.

[3] Richter, K. (1968) Die chirurgische anatomie der vaginae fixation sacrospinalis vaginalis. Ein beitrag zur operation behandlung des scheidenblindsachprolapses. Geburtshilfe Frauenheilkd, 28, 321-327.

[4] Estrade, J.-P., Agostini, A., Roger, V., Dallay, D., Blanc, B. and Cravello, L. (2005) Résultats de la sacrospinofixation dans le traitement des prolapsus après hystérectomie. Journal de Gynécologie Obstétrique et Biologie de la Reproduction, 34, 481-487. https://doi.org/10.1016/S0368-2315(05)82856-X

[5] Pohl, J.F. and Frattarelli, J.L. (1997) Bilateral Transvaginal Sacrospinous Colpopexy: Preliminary Experience. American Journal of Obstetrics \& Gynecology, 177, 1356-1362. https://doi.org/10.1016/S0002-9378(97)70075-9

[6] David-Montefiore, E., Barranger, E. and Dubernard, G. (2007) Functional Results and Quality-of-Life after Bilateral Sacrospinous Ligament Fixation for Genital Prolapse. European Journal of Obstetrics and Gynecology and Reproductive Biology, 132, 209-213. https://doi.org/10.1016/j.ejogrb.2006.04.031

[7] Ranney, B. (1981) Enterocele, Vaginal Prolapse, Pelvic Hernia: Recognition and Treatment. American Journal of Obstetrics \& Gynecology, 140, 53-61. https://doi.org/10.1016/0002-9378(81)90257-X

[8] Cruikshank, S.H. (1991) Sacrospinous Fixation-Should This Be Performed at the Time of Vaginal Hysterectomy? American Journal of Obstetrics \& Gynecology, 164, 1072-1076. https://doi.org/10.1016/0002-9378(91)90588-I

[9] Cruikshank, S.H. and Cox, D.W. (1990) Sacrospinous Ligament Fixation at the Time of Transvaginal Hysterectomy. American Journal of Obstetrics \& Gynecology, 162, 1611-1615. https://doi.org/10.1016/0002-9378(90)90927-Y

[10] Phaneuf, L.E. (1952) Inversion of the Vagina and Prolapse of the Cervix Following Supracervical Hysterectomy and Inversion of the Vagina Following Total Hysterectomy. American Journal of Obstetrics \& Gynecology, 64, 739-745. https://doi.org/10.1016/S0002-9378(16)38793-2

[11] Estrade, J.-P., Agostini, A., Roger, V., Dallay, D., Blanc, B. and Cravello, L. (2004) Les complications de la sacrospinofixation. Gynécologie Obstétrique \& Fertilité, 32, 850-854. https://doi.org/10.1016/S1297-9589(04)00264-4

[12] Cravello, L., Agostini, A., Estrade, J.-P., Roger, V. and Blanc, B. (2008) Blanc Techniques, indications et résultats de la sacrospinofixation uni et bilatérale. Pelvi-Périnéologie, 3 , 309-313. https://doi.org/10.1007/s11608-008-0212-y

[13] Richter, K. and Albrich, W. (1981) Long-Term Results Following Fixation of the Vagina on the Sacrospinal Ligament by the Vaginal Route (Vaginae Fixatio Sacrospinalis Vaginalis). American Journal of Obstetrics \& Gynecology, 141, 811-816. https://doi.org/10.1016/0002-9378(81)90709-2 